\title{
Efeito do consórcio e da adubação orgânica na produtividade do algodão herbáceo BRS Aroeira
}

\author{
Sebastiana Joelma de Azevedo Santos ${ }^{1}$; Nair Helena Castro Arriel ${ }^{2}$; José da Cunha Medeiros ${ }^{2}$; Ednalva \\ Araújo do Nascimento ${ }^{2}$; Francisco Germano Barros da Silva ${ }^{3}$; Vanderléia Fernanda dos Santos Araújo
}

\begin{abstract}
${ }^{1}$ Universidade Estadual da Paraíba, ajoelma65@gmail.com, vanderleiafernanda@gmail.com; ${ }^{2}$ Embrapa Algodão, nair.arriel@embrapa.br; jose.medeiros@embrapa.br; ednalva.nascimento155@gmail.com; ${ }^{3}$ Universidade Federal de Campina Grande, germano.2006@hotmail.com.
\end{abstract}

RESUMO: O algodoeiro (Gossypium hirsutum) é uma planta bem adaptada a regiões semiáridas, podendo ser cultivada com práticas comuns de base agroecológica. A pesquisa foi desenvolvida na Fazenda Agroecológica Dulinos no ano agrícola de 2018. Os ensaios foram conduzidos em delineamento de blocos ao acaso (DBC), no esquema fatorial $4 \times 2$, com 4 repetições, estabelecidos em oito tratamentos, constituídos de quatro arranjos populacionais (algodão + palma forrageira; algodão + feijão macassar; algodão + milho e algodão solteiro) na presença e ausência de adubação orgânica (esterco bovino). Objetivou-se avaliar a produtividade do algodão herbáceo BRS Aroeira, consorciado com diferentes culturas, na presença e ausência de esterco bovino. Foram avaliados o peso do capulho, caroço, pluma e pluma com caroço. No que diz respeito à produtividade de pluma e caroço, a palma é a espécie indicada para consorciar com o algodão herbáceo BRS Aroeira. A adubação orgânica eleva a produtividade $\mathrm{Kg} \mathrm{ha}^{-1}$ do algodão herbáceo BRS Aroeira.

PALAVRAS-CHAVE: Algodoeiro; Consorciação; Esterco bovino; Manejo agroecológico.

\section{INTRODUÇÃO}

O algodoeiro (Gossypium hirsutum) é uma planta bem adaptada a regiões semiáridas, por ser tolerante a seca, sendo uma das principais culturas exploradas no Brasil. O manejo de cultivos consorciados e a adubação orgânica são práticas comuns da agricultura familiar de base agroecológica.

O algodão é uma das plantas mais importantes para a produção de fibras, além de ser fonte de alimento animal e matéria prima para a produção de óleo, a partir de suas sementes. Para garantir a evolução do setor, é imprescindível o uso de tecnologias eficientes, com foco na melhoria da produtividade e na qualidade do algodão, favorecendo o desenvolvimento sustentável da cultura (CONAB, 2017). De acordo com o IBGE (2017), a produção de algodão herbáceo em 2017 (3.825.902 t) teve um aumento de 7,7 \% na safra em relação ao ano de 2016 (3.462.647 t). O cultivo do algodão se adequa a agricultura familiar, uma vez que, pode ser consorciada com culturas alimentares como milho e feijão, além de plantas forrageiras.

Nos últimos anos, fontes alternativas de adubação orgânica não só para o cultivo de algodão, como para as demais culturas, têm despertado o interesse, tanto dos produtores quanto dos pesquisadores. De acordo com Silva, et al. (2005), um dos adubos orgânicos mais utilizados na agricultura nordestina é o esterco, principalmente bovino, porém sua eficiência depende do grau de decomposição, da origem do material, da dosagem empregada e até da forma de colocação do adubo.

Dessa forma, o presente trabalho objetivou avaliar a produtividade do algodão herbáceo BRS Aroeira, consorciado com diferentes culturas, na presença e ausência de esterco bovino como fonte de adubação orgânica no Seridó Paraibano.

\section{MATERIAL E MÉTODOS}

A pesquisa foi desenvolvida na Fazenda Agroecológica Dulinos no ano agrícola de 2018, situada no sítio Serrote Verde, município de Baraúna, Estado da Paraíba, a $6^{\circ} 38^{\prime} 34^{\prime}$ 'S de latitude e $36^{\circ} 15^{\prime} 14^{\prime \prime} \mathrm{W}$ de longitude, em uma área correspondente a, aproximadamente, 0,5 ha.

Os ensaios foram conduzidos em delineamento de blocos ao acaso (DBC), estabelecidos em oito tratamentos, constituídos de quatro arranjos populacionais (algodão + palma forrageira; algodão + feijão macassar; algodão + milho e algodão solteiro) na presença e ausência de adubação orgânica (esterco bovino), distribuídos em esquema fatorial 4 x 2 com quatro repetições.

\section{Descrição dos agroecossistemas}

Agrossistema 1: Consórcio de algodão e palma forrageira. A palma foi plantada no espaçamento de $2,0 \times 0,5 \mathrm{~m}$, no qual se intercalou uma fileira de algodão no espaçamento de $1,0 \times 0,25 \mathrm{~m}$ entre a palma forrageira.

Agrossistema 2: Consórcio algodão e feijão macassar. O algodão foi plantado no espaçamento de 2,0 x $0,25 \mathrm{~m}$, no qual se intercalou uma fileira de feijão macassar no espaçamento de 1,0 × $0,25 \mathrm{~m}$ entre as fileiras de algodão.

Agrossistema 3: Consórcio de algodão e milho. O algodão foi plantado no espaçamento de 2,0 x 0,25 m, no qual se intercalou uma fileira de milho no espaçamento de $1,0 \times 0,25 \mathrm{~m}$ entre as fileiras de algodão.

Caderno Verde de Agroecologia e Desenvolvimento Sustentável (ISSN 2358-2367) v. 9, n.7, e-7064, 2019 
SANTOS, S. J. A. et al. Efeito do consórcio e da adubação orgânica na produtividade do algodão herbáceo BRS Aroeira. In: II Congresso Paraibano de Agroecologia \& IV Exposição Tecnológica, 2019. Anais... Caderno Verde de Agroecologia e Desenvolvimento Sustentável, Pombal, v. 9, n.7, e-7064, 2019.

Agrossistema 4: Algodão solteiro com espaçamento de 1,0 x 0,25 m.

Todas as parcelas tiveram área de $24 \mathrm{~m}^{2}$, sendo a área útil das parcelas de $8 \mathrm{~m}^{2}$. Foram avaliadas vinte amostras padrão por área útil estimando-se as produtividades em $\mathrm{kg}$ ha- ${ }^{1}$.

O algodão, o feijão e o milho foram semeados 41 dias após o plantio da palma forrageira. A palma foi plantada no final do mês de fevereiro e o algodão e as culturas alimentares no início do mês de abril. As colheitas ocorreram nos meses de julho, agosto e setembro para o feijão, o milho e o algodão, respectivamente. E a coleta das brotações da palma, como parâmetro de produtividade, ocorreu 205 DAP.

O experimento foi conduzido com base em sistemas de cultivo orgânico, dentro de uma proposta agroecológica. Foi realizada adubação orgânica de fundação por metro linear com esterco bovino para as parcelas com a fertilização, simultaneamente ao dia do plantio.

Nos agroecossistemas foram escolhidas as seguintes cultivares: algodão (Gossypium hirsutum L. cv. BRS. Aroeira), palma forrageira (Opuntia ficus indica (L.) P. Mill - cv, Gigante), milho (Zea mays) e feijão macassar (Vigna unguiculata). Para a semeadura do algodão, do milho e do feijão foram utilizadas 5 sementes de cada cultivar em covas com aproximadamente $2 \mathrm{~cm}$ de profundidade. O desbaste ocorreu 30 dias após a semeadura (DAS). As colheitas foram realizadas ao final do ciclo de cada cultura, com exceção da palma forrageira que é uma cultura perene. Já para a palma forrageira foi plantada uma raquete em cada cova. A coleta de dados foi feita após a colheita do milho, do feijão e do algodão.

Foram analisadas as variáveis peso do capulho, caroço, pluma e pluma com caroço. Os dados obtidos foram avaliados por análise de variância sendo aplicado o teste de comparação de médias (Tukey, p < 0,05) utilizando-se do software SISVAR 5.6. Foi utilizado os recursos do Microsoft @ Office Excel para elaboração das figuras.

\section{RESULTADOS E DISCUSSÃO}

Verifica-se na (tabela 1) que a interação adubação orgânica e diferentes agroecossistemas não exerceu significância estatística, nas variáveis peso de 1 capulho; caroço e pluma, mas que as variáveis responderam aos efeitos isolados da adubação orgânica e dos agroecossistemas na produtividade do algodoeiro herbáceo BRS aroeira.

Tabela 1 - Quadrados médio referente às variáveis peso de 1 capulho $(\mathrm{g})$, caroço $\left(\mathrm{Kg} \mathrm{ha}^{-1}\right)$ e pluma $\left(\mathrm{Kg}_{\mathrm{g}} \mathrm{h}^{-1}\right)$ de plantas de algodão cultivado sob diferentes agroecossistemas e uso de adubação orgânica.

\begin{tabular}{|c|c|c|c|c|}
\hline \multirow[b]{2}{*}{ Fonte de variação } & \multicolumn{4}{|c|}{ Quadrado médio } \\
\hline & GL & Peso de 1 capulho & Caroço & Pluma \\
\hline Adubação orgânica (Ad) & 1 & $5,2 * *$ & $333 * *$ & $65,57 * *$ \\
\hline Agroecossistemas (Ag) & 1 & $1,35^{*}$ & $97 *$ & $19,11^{*}$ \\
\hline Int. Ad x Ag & 1 & $0,11 \mathrm{~ns}$ & $7 \mathrm{~ns}$ & $2,12 \mathrm{~ns}$ \\
\hline Bloco & 3 & $0,31 \mathrm{~ns}$ & $21 \mathrm{~ns}$ & $3,94 \mathrm{~ns}$ \\
\hline Resíduo & & 0,37 & 26 & 4,59 \\
\hline $\mathrm{CV}(\%)$ & & 15,94 & 16,18 & 16,49 \\
\hline
\end{tabular}

$\mathrm{GL}=$ Grau de liberdade; $\mathrm{CV}=$ Coeficiente de variação; $\mathrm{ns}=$ não significativo; ${ }^{*} \mathrm{p}<0,05 ; * * \mathrm{p}<0,01$.

De acordo com a análise de variância (Tabela 1), a adubação orgânica exerceu significância estatística $(\mathrm{P}<0,01)$ e o cultivo do algodão em diferentes agroecossistemas $(\mathrm{P}<0,05)$. Esses dados corroboram com os de Souza et al. (2018) que ao realizarem trabalho com algodão cv. BRS Jady observaram que a adubação orgânica promoveu o aumento do crescimento e produção do algodão.

\section{Peso de 1 capulho}

O peso de 1 capulho em plantas de algodão herbáceo BRS Aroeira foi afetado positivamente pela utilização da adubação orgânica. Os pesos variaram de 4,23 g a 3,42 g (Figura 1) nos agroecossistemas sem e com o adubo orgânico, respectivamente.

O aumento no rendimento do peso de capulho do algodão com o uso do adubo orgânico (esterco bovino), possivelmente seja expressão dos efeitos positivos deste insumo na melhoria física do ambiente edáfico, com fornecimento equilibrado de macro e micronutrientes, do estímulo à ação de proteínas, de celulose, de fitormônios e solutos orgânicos (TORRES et al., 2014). 
SANTOS, S. J. A. et al. Efeito do consórcio e da adubação orgânica na produtividade do algodão herbáceo BRS Aroeira. In: II Congresso Paraibano de Agroecologia \& IV Exposição Tecnológica, 2019. Anais... Caderno Verde de Agroecologia e Desenvolvimento Sustentável, Pombal, v. 9, n.7, e-7064, 2019.

Figura 1 - Peso de 1 capulho de algodão herbáceo BRS Aroeira cultivado com e sem o uso de adubação orgânica.

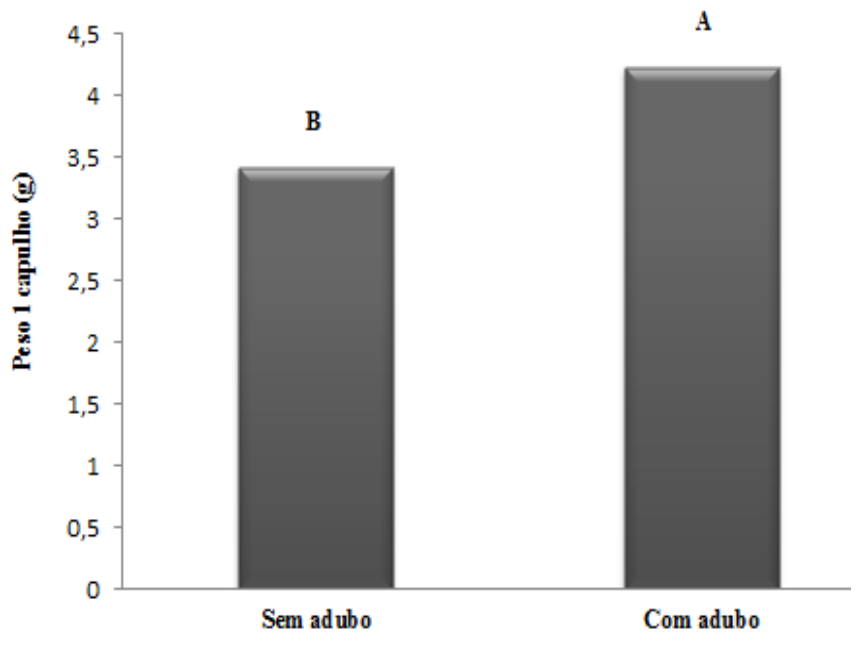

Quando se comparou o cultivo do algodão BRS Aroeira isolado com o cultivo do algodão consorciado em diferentes agroecossistemas (Figura 2), verificou-se diferença estatística $(\mathrm{P}<0,05)$. O peso de 1 capulho da malvácea quando consorciado com a palma apresentou o maior peso $(4,25 \mathrm{~g})$ e o menor peso foi encontrado no agroecossistema em que foi cultivado simultaneamente com o feijão, representando um decréscimo de $18,28 \%$ em relação ao rendimento do cultivo solteiro $(4,05 \mathrm{~g})$.

Figura 2 - Peso de 1 capulho de algodão herbáceo BRS Aroeira cultivado em diferentes agroecossistemas.

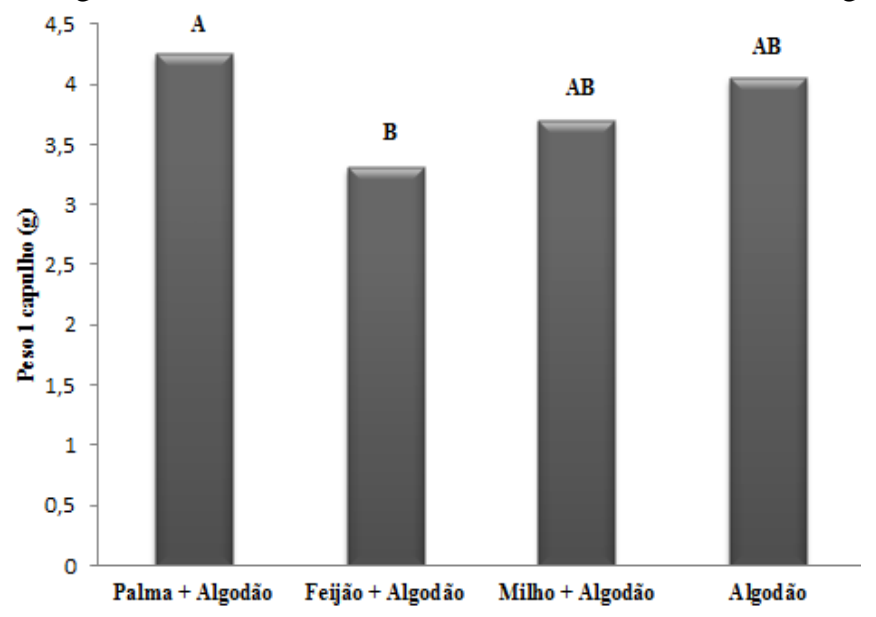

É possível que essa redução expressiva no peso de 1 capulho do algodoeiro, seja um indicativo de competição exercida pelo feijão, quando semeados no mesmo dia, devido, principalmente, a maior taxa de crescimento inicial deste em relação ao algodão, visto que as condições de cultivo foram semelhantes. Desta forma recomenda-se que o cultivo consorciado seja realizado com intervalo entre o plantio do algodão para o feijão, minimizando assim a competição entre as culturas. Resultados semelhantes ao deste trabalho foram encontrados por Beltrão et al. (1986) que ao avaliarem algodoeiro herbáceo em consórcio com cultivares de feijão caupi. As espécies do feijão caupi e algodão apresentaram forças de competição interespecíficas.

\section{Pluma}

De acordo com a (Figura 3), a aplicação da adubação orgânica elevou o rendimento de pluma de algodão em aproximadamente $20 \%$, com valores de $11,56 \mathrm{Kg} / \mathrm{ha}$ (sem) a 14,42 Kg/ha (com adubo).

Esses dados corroboram com os de Ferreira et al. (2018) que ao estudarem o crescimento e produtividade do algodoeiro herbáceo submetido à adubação orgânica observaram que o uso de esterco bovino ocasionou aumento na produtividade de fibra de algodão em relação a não utilização de adubação orgânica. A utilização de esterco bovino tem proporcionado os melhores resultados produtivos às culturas devido à retenção de água na matéria orgânica. 
SANTOS, S. J. A. et al. Efeito do consórcio e da adubação orgânica na produtividade do algodão herbáceo BRS Aroeira. In: II Congresso Paraibano de Agroecologia \& IV Exposição Tecnológica, 2019. Anais... Caderno Verde de Agroecologia e Desenvolvimento Sustentável, Pombal, v. 9, n.7, e-7064, 2019.

Figura 3 - Produtividade em pluma do algodão herbáceo BRS Aroeira cultivado com e sem o uso de adubação orgânica.

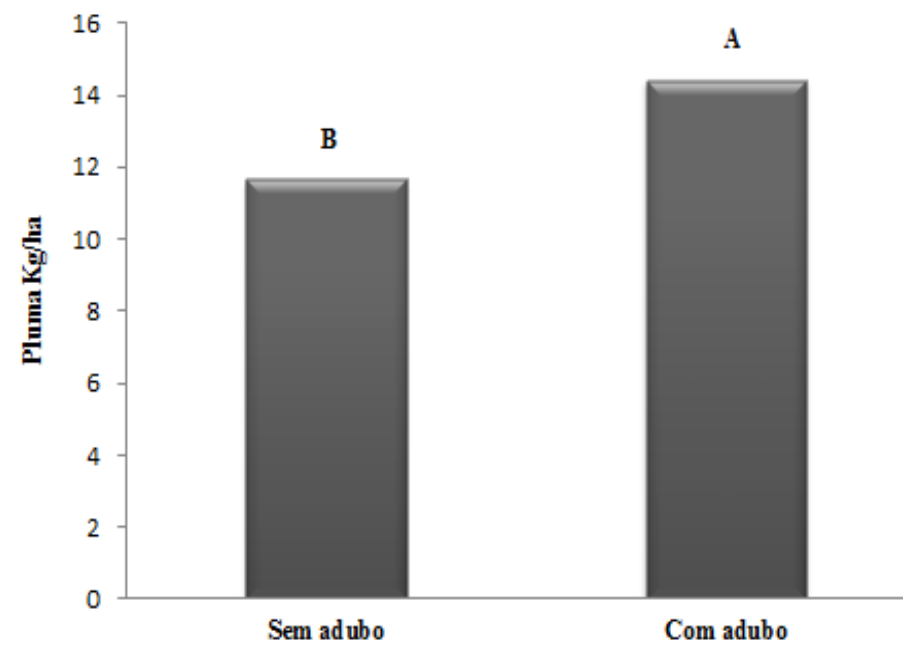

Comparando-se o agroecossistema algodão solteiro em relação ao consorciado com milho, ambos não apresentaram diferença estatística para o rendimento em pluma (Figura 4), mas constatou-se maior rendimento no agroecossistema solteiro $\left(13,85 \mathrm{Kg} \mathrm{ha}^{-1}\right)$. Esta variação foi de $11 \%$, com diferença de $1,41 \mathrm{Kg}^{-1}$ em relação ao agroecossistema consorciado com o milho. Porém, sabe-se que no consórcio entre duas culturas a busca pelos recursos do ambiente se torna mais competitivo e escasso, o que reduz o rendimento das espécies no consórcio e privilegia, em alguns casos, a cultura isolada.

Figura 4 - Produtividade em pluma do algodão herbáceo BRS Aroeira cultivado em diferentes agroecossistemas

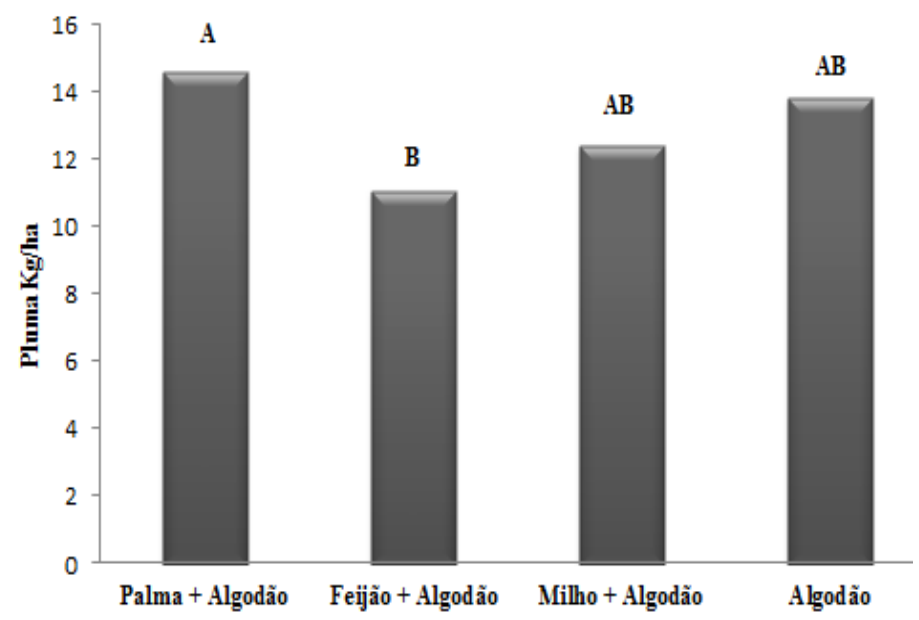

Oliveira Filho et al. (2016) pesquisando a eficiência agronômica nos consórcios da mamoneira com milho observaram que o rendimento da mamoneira consorciada com milho foi inferior ao cultivo solteiro, que superou a produtividade em 1.138,28 $\mathrm{kg} \mathrm{ha}^{-1}$ e $952,08 \mathrm{~kg} \mathrm{ha}^{-1}$, concluindo que a consorciação reduziu o rendimento da gramínea em $204,02 \mathrm{~kg} \mathrm{ha}^{-1}$.

\section{Caroço}

Conforme a (Figura 5), as plantas de algodão herbáceo BRS Aroeira que não receberam a adubação orgânica tiveram um baixo rendimento na produção de caroço $\mathrm{Kg} / \mathrm{ha}$ em $18,55 \%$ com uma redução de $34,84 \mathrm{Kg}^{\mathrm{h}} \mathrm{ha}^{-1}$ (com adubo) para $28,38 \mathrm{Kg} / \mathrm{ha}^{-1}$ (sem adubo).

Ferreira et al. (2018) comprovaram em seus estudos que o esterco bovino aumentou em $108 \%$ a produtividade de caroço de algodão em relação a não utilização de adubação orgânica. A utilização de matéria orgânica melhora a estrutura física (porosidade) e química (disponibilidade de nutrientes) do solo, possibilitando o melhor desenvolvimento das plantas (GOMES et al., 2019), refletindo consequentemente no rendimento de caroço $\mathrm{Kg} / \mathrm{ha}^{-1}$ nas plantas de algodão. 
SANTOS, S. J. A. et al. Efeito do consórcio e da adubação orgânica na produtividade do algodão herbáceo BRS Aroeira. In: II Congresso Paraibano de Agroecologia \& IV Exposição Tecnológica, 2019. Anais... Caderno Verde de Agroecologia e Desenvolvimento Sustentável, Pombal, v. 9, n.7, e-7064, 2019.

Figura 5- Produtividade em caroço do algodão herbáceo BRS Aroeira cultivado com e sem o uso de adubação orgânica.

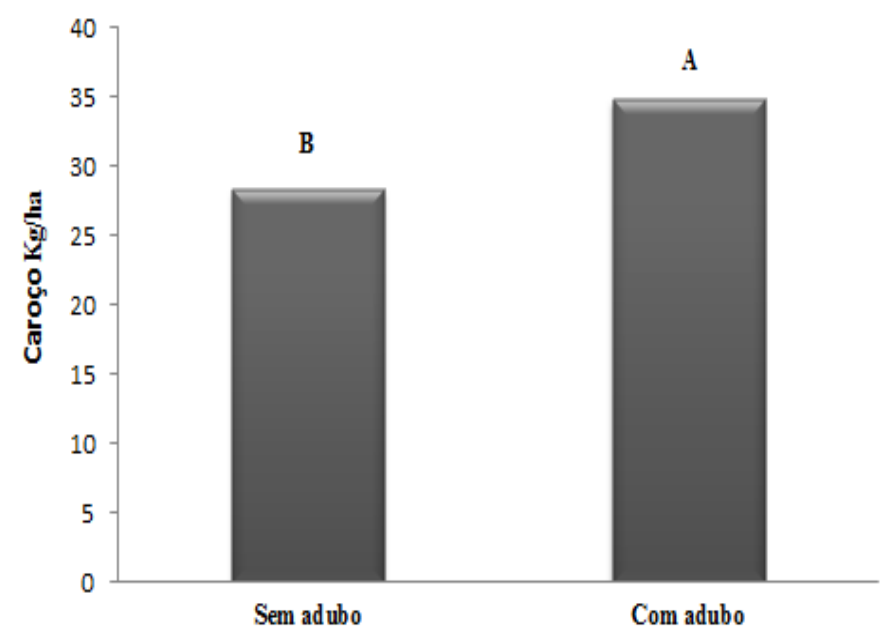

Ao observar os resultados de rendimento em caroço do algodão em consórcio com feijão e o rendimento de algodão cultivado solteiro não notou-se diferença significativa entre os agroecossistemas (Figura 6), obtendo-se o rendimento de caroço para o cultivo solteiro estimado em $33,49 \mathrm{Kg} / \mathrm{ha}^{-1}$. Apesar de não haver diferença estatística entre os agroecossistemas, observou-se que houve uma ligeira competição entre as espécies consorciadas feijão e algodão. Provavelmente a competitividade entre as plantas reduziu o rendimento de caroço em $\mathrm{Kg} / \mathrm{ha}^{-1}$ das plantas de algodão de $33,49 \mathrm{Kg} / \mathrm{ha}^{-1}$ quando cultivado solteiro para $27,29 \mathrm{Kg} / \mathrm{ha}^{-1}$ cultivo consorciado com feijão.

Figura 6 - Produtividade em caroço do algodão herbáceo BRS Aroeira cultivado em diferentes agroecossistemas.

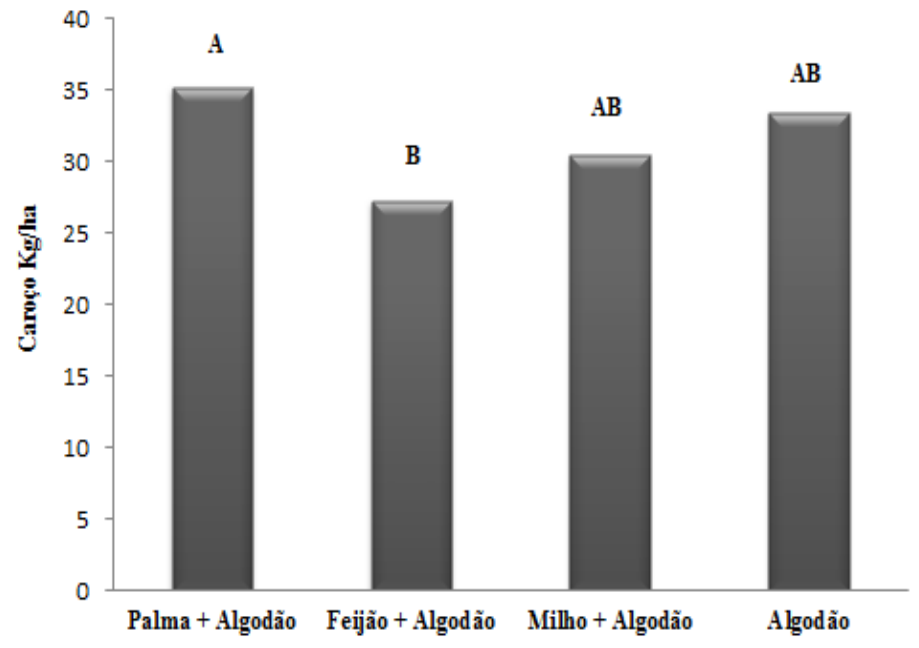

Consórcios são considerados sistemas mais produtivos, tanto pelo aumento da produção por unidade de área, quanto pelo aumento da eficiência no uso dos recursos e melhoria da renda do produtor (MEDEIROS, et al., 2019). Problemas relacionados a configurações de plantio, escolha das culturas consortes, épocas relativas de plantio e manejo do solo podem influenciar a competição interespecífica (SILVA, CHARLLEY et al., 2018).

A escolha das culturas consortes, em especial, é um fator crítico para a estabilização das relações competitivas estabelecidas nos consórcios com implicações diretas no rendimento de cada cultura, no aproveitamento da área e na conservação do solo (ARAÚJO et al., 2016), mas não implica dizer que o agroecossistema é inviável pelo baixo rendimento da cultura principal. É preciso levar em consideração o preço de mercado das culturas envolvidas.

\section{CONCLUSÕES}

A palma é a espécie indicada para consorciar com o algodão herbáceo BRS Aroeira.

A adubação orgânica eleva a produtividade $\mathrm{Kg} /$ ha $^{-1}$ do algodão herbáceo BRS Aroeira. 
SANTOS, S. J. A. et al. Efeito do consórcio e da adubação orgânica na produtividade do algodão herbáceo BRS Aroeira. In: II Congresso Paraibano de Agroecologia \& IV Exposição Tecnológica, 2019. Anais... Caderno Verde de Agroecologia e Desenvolvimento Sustentável, Pombal, v. 9, n.7, e-7064, 2019.

\section{REFERÊNCIAS}

ARAÚJO, A. C.; AlOUFA, M. A. I.; SILVA, A. J. N.; ARAÚJO, A. C. Competição interespecífica e viabilidade econômica do consórcio gergelim-feijão caupi em sistema orgânico de cultivo em função de épocas de semeadura. Revista Brasileira de Agroecologia, v. 11, n. 2, p. 110-116, 2016.

BELTRÃO, N. E. M.; NÓBREGA, L. B.; AZEVÊDO, D. M. P.; VIEIRA, D. J.; CRISÓSTOMO, J. R. Algodoeiro herbáceo em consórcio com cultivares de caupi. Pesquisa agropecuária brasileira, v 21 n 3, p. 271-284, 1986.

CONAB, Companhia Nacional de Abastecimento. Acompanhamento da Safra Brasileira: Algodão. $4^{\circ}$ levantamento de grãos. Brasília: Conab, 2017. Disponível em: http://www.conab.gov.br/OlalaCMS/uploads/arquivos /12_07_10_08_42_35_algodao02a06072017 pdf. Acesso em: 04 Dez. de 2017.

FERreirA, M. M.; TARTAGliA, F. L.; FUlAnETI, F. S.; ALENCAR, C. C.; SANTOS, E. M.; ALVES G. S. Crescimento e produtividade do algodoeiro herbáceo submetido à adubação orgânica. Revista Brasileira de Agropecuária Sustentável, v.8, n.2, p.52-61, 2018.

GOMES, L. A.; SILVA, F. D. A.; PEREIRA, F. H. F.; JUNIOR, J. E. C.; NOBREGA, J. S. Crescimento inicial do milho sob aplicação de esterco bovino. Revista Ambientale, v. 11, n. 2, p. 12-21, 2019.

IBGE. INSTITUTO BRASILEIRO DE GEOGRAFIA E ESTATÍSTICA. 2017. Disponível em: https://agenciadenoticias.ibge.gov.br/agencia-noticias/2013-agencia-de-noticias/releases/17171-em-setembro-ibgepreve-safra-de-graos-30-3-superior-a-2016.html. Acesso em 06/12/2017.

MEDEIROS, M. L. S.; DEMARTELAERE, A. C. F.; LIMA, J. S. S.; SILVA, M. L.; PÁDUA, G. V. G. Consorciação de caupi-hortaliça e beterraba sob diferentes quantidades de flor-de-seda incorporadas ao solo. Revista Verde de Agroecologia e Desenvolvimento Sustentável, v. 14, n. 1, p. 12-20, 2019.

OLIVEIRA FILHO, A. F.; BEZERRA, F. T. C.; PITOMBEIRA, J. B.; DUTRA, A. S.; BARROS, G. L. Agronomic and biological efficiency in the castor bean intercropped with cowpea or maize. Journal Agronomic Science, v. 47, n. 4, p. 729-736, 2016.

SILVA, CHARLlEY. F.; MEDEIROS, E. V.; SANTANA, M. D.; ARAÚJO, M. B.; MARTINS FILHO, A. P.; MOURA, M. F. Atividade microbiológica do solo e produtividade do milho adubado com leguminosas e doses de esterco. Revista Caatinga, v. 31, n. 4, p. 882-890, 2018.

SILVA, M. N. B.; BELTRÃO, N. E. M.; D. CARDOSO, G. D. Adubação do algodão colorido BRS 200 em sistema orgânico no Seridó Paraibano. Revista Brasileira de Engenharia Agrícola e Ambiental, v.9, n.2, p.222-228, 2005.

SOUZA, L. P.; LIMA, G. S.; GHEYI, H. R.; NOBRE, R. G.; SOARES, L. A. A. Emergence, growth, and production of colored cotton subjected to salt stress and organic fertilization. Journal Caatinga, v. 31, n. 3, p. 719 - 729, 2018.

TORRES, E. C. M.; FREIRE, J. L. O.; OLIVEIRA, J. L., BANDEIRA, L. B.; MELO, D. A.; SILVA, A. L. Biometria de mudas de cajueiro anão irrigadas com águas salinas e uso de atenuadores do estresse salino. Revista Nativa, v. 2 , n. 2, p. 71-78, 2014.

\section{AGRADECIMENTOS}

Apoio financeiro: Fundação de Apoio à Pesquisa do Estado da Paraíba - FAPESQ. 